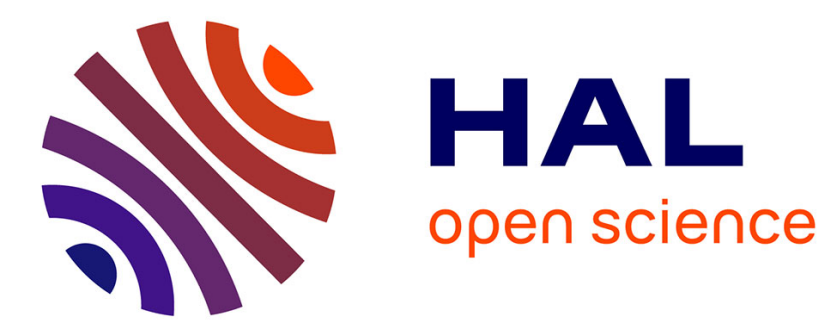

\title{
Atrophy of the Residual Alveolar Ridge Following Tooth Loss in a Historical Population
}

Karoline Maria Reich, Christian Domitian Huber, Wilburg Reingard Lippnig, Christian Ulm, Georg Watzek, Stefan Tangl

\section{- To cite this version:}

Karoline Maria Reich, Christian Domitian Huber, Wilburg Reingard Lippnig, Christian Ulm, Georg Watzek, et al.. Atrophy of the Residual Alveolar Ridge Following Tooth Loss in a Historical Population. Oral Diseases, 2010, 17 (1), pp.33. 10.1111/j.1601-0825.2010.01699.x . hal-00599901

\section{HAL Id: hal-00599901 https://hal.science/hal-00599901}

Submitted on 11 Jun 2011

HAL is a multi-disciplinary open access archive for the deposit and dissemination of scientific research documents, whether they are published or not. The documents may come from teaching and research institutions in France or abroad, or from public or private research centers.
L'archive ouverte pluridisciplinaire HAL, est destinée au dépôt et à la diffusion de documents scientifiques de niveau recherche, publiés ou non, émanant des établissements d'enseignement et de recherche français ou étrangers, des laboratoires publics ou privés. 


\section{ORALIDISEASES}

\section{Atrophy of the Residual Alveolar Ridge Following Tooth Loss in a Historical Population}

\begin{tabular}{|r|l|}
\hline Journal: & Oral Diseases \\
\hline Manuscript ID: & ODI-10-09-OM-1432.R2 \\
\hline Manuscript Type: & Original Manuscript \\
\hline Author: & 12 -Feb-2010 \\
\hline Complete List of Authors: & $\begin{array}{l}\text { Reich, Karoline; Medical University of Vienna, Department of Oral } \\
\text { Surgery; Autrian Cluster for Tissue Regeneration } \\
\text { Huber, Christian; Medical University of Vienna, Department of Oral } \\
\text { Surgery; Austrian Cluster for Tissue Regeneration } \\
\text { Lippnig, Wilburg; Medical University of Vienna, Department of Oral } \\
\text { Surgery } \\
\text { Ulm, Christian; Medical University of Vienna, Department of } \\
\text { Periodontology } \\
\text { Watzek, Georg; Medical University of Vienna, Department of Oral } \\
\text { Surgery; Austrian Cluster for Tissue Regeneration } \\
\text { Tangl, Stefan; Medical University of Vienna, Department of Oral } \\
\text { Surgery; Austrian Cluster for Tissue Regeneration }\end{array}$ \\
\hline Keywords: & \begin{tabular}{l} 
Pathology, Craniofacial, jaw atrophy, alveolar ridge resorption \\
\hline
\end{tabular} \\
\hline \hline
\end{tabular}

\section{ScholarONE" \\ Manuscript Central}


1

2

4

5

6

7

8

9

\section{Atrophy of the Residual Alveolar Ridge Following Tooth Loss in an Historical Population}

Running title: Natural course of jaw atrophy

\section{Keywords:}

jaw atrophy; alveolar ridge resorption; tooth loss; residual ridge; denture adverse effects; dental implants; pathoaetiology

Name(s) and address(es) of author(s):

Karoline M. Reich ${ }^{1,2}$, Christian D. Huber ${ }^{1,2}$, Wilburg R. Lippnig ${ }^{1}$, Christian Ulm ${ }^{3}$, Georg Watzek ${ }^{1,2}$, Stefan Tangl ${ }^{1,2}$

${ }^{1}$ Department of Oral Surgery, Medical University of Vienna, Austria

${ }^{2}$ Austrian Cluster for Tissue Regeneration, Vienna, Austria

${ }^{3}$ Department of Periodontology, Medical University of Vienna, Austria

\section{Corresponding author:}

Stefan Tangl

Department of Oral Surgery, Medical University of Vienna, Austria

Währingerstraße $25 \mathrm{a}$

1090 Vienna

Austria

Tel: +43-1-4277-67028; Fax: +43-1-4277-67019

stefan.tangl@meduniwien.ac.at

Date of submission:

$29^{\text {th }}$ October, 2009 


\title{
Atrophy of the Residual Alveolar Ridge Following Tooth Loss in an
}

\author{
Historical Population
}

\begin{abstract}
Objectives: To study the natural aetiopathology of jaw atrophy after tooth loss, unaltered by prosthetic procedures, an historical population without modern dental treatment was examined.

Methods: Based on the hypothesis that there are predictable changes in shape during jaw-atrophy, frequency and degree of atrophy as well as clinical aspects of bone quality and resorption were determined in the skeletal remains of 263 individuals. The potential association between age and frequency/severity of atrophy was analysed.

Results: Atrophy in at least one jaw segment was present in $45.2 \%$ of the analysed jaw specimens. The residual ridge underwent a series of changes in shape and height following the pattern of resorption described for modern populations. The severity of these alterations was associated with the age of the individual and the region within the jaw. Atrophy was frequently related to structural degradation of the covering cortical layer.

Conclusions: These findings prove that atrophy of the jaw evidently does occur, displaying similar patterns of resorption in a population without modern prosthetics, where the negative effect of ill-fitting dentures is excluded. The basic information about alterations of shape and the cortical layer covering the residual crest might help to provide a deeper insight into aetiopathological mechanisms of this common oral disease.
\end{abstract}




\section{Introduction}

As people grow progressively older in modern societies, health problems associated with advanced age increase dramatically. These include, among others, oral diseases that finally may lead to tooth loss and necessitate prosthetic treatment for the patient to obtain the ability to chew and eat as normally as possible.

Tooth loss may have a variety of causes such as periodontal disease, caries and trauma leading to pulpitis. Whatever the reason might be, the effect of tooth loss is always the same: The physiologic masticatory forces applied via the roots of teeth to the cancellous alveolar bone no longer persist (Devlin \& Ferguson, 1991; Ulm et al., 1997). According to Wolff's Law (Wolff, 1892) and the Mechanostat Model (Frost, 2003) disuse and a loss of mechanical stimulation is followed by the reduction of bone mass. This effect was originally demonstrated for limb bones. If these models also hold true for the alveolar process of the jaw and other regions of the skull remains to be investigated in more detail. Also the influence of other factors such as regionally different gene expression (long bones vs. cranial vault) resulting in site-specific osteoblast behavior, osteoclast activity and matrix composition has been discussed in this context recently (Rawlinson et al., 2009). However, loss of teeth leads invariably to atrophy of the residual alveolar ridge being irreversible, chronic, progressive and cumulative (Atwood, 1971).

The rate of atrophy varies greatly between different individuals (Bras, 1990) and even within one and the same person at different times or in different regions within the jaw (Atwood, 1971; Atwood, 1973). However, atrophy is greatest during the first year after tooth loss; the reduction of the residual ridge is a lifelong process (Sennerby et al., 1988) but the rate of bone loss does decrease (Denissen et al., 1993).

Atrophy of the jaw bone can be slowed down, but unfortunately not eliminated, with the help of an appropriate treatment using prostheses balancing the loads to the underlying bone or preferably using implant-supported overdentures (Kordatzis et al., 2003) or endosseous implants (Jokstad et al., 2000a; Jokstad et al., 2000b; Bodic et al., 2005).

Yet, the influence of fixed or removable dentures is an issue of controversial discussion (Devlin \& Ferguson, 1991; Carlsson, 2004). As complete dentures do not load the alveolus in the same way as the original teeth do, non-physiologic pressure is applied to the bone surface of the affected jaw, which might be a reason for increased resorption. This is particularly plausible for ill-fitting dentures that cause occlusal disharmonies and thus might enhance alveolar bone loss (Devlin \& Ferguson, 1991). Hence the quality of the denture as a holistic system is crucial to prevent local overloading of the underlying bone (Xie et al., 1997a).

However, reduction of the height of the residual ridge is also observed in patients without denture treatment (Devlin \& Ferguson, 1991). Consequently, atrophy of the alveolar bone is not attributable to prosthetic factors alone (Atwood, 1979).

Anatomic conditions of the jaws, systemic factors such as sex and age, hormonal balance, local inflammations and masticatory habits are supposed to act as co-factors in the development of residual ridge resorption after tooth loss (Atwood, 1971; Gruber et al., 1993; Kingsmill, 1999).

To gain information about the pathology of atrophy of the jawbone after tooth loss unaltered by the influence of prosthetic procedures, a population without modern dental treatment seems appropriate to serve as a model. For this reason, the skeletal remains of a central European population unearthed from a mediaeval cemetery of the 7th-8th century A.D. was used for this study. As dental treatment was not or only rarely practised in mediaeval populations (Watt et al., 1997; Vodanovic' et al., 2005), these skeletal remains are very useful for analysing the pure effect of oral diseases such as jaw atrophy on the residual ridge.

The purpose of this study is to characterise the patterns of jaw atrophy after tooth loss in an historical population without modern dentistry using an adapted classification system according to Atwood (Atwood, 1963) and Cawood and Howell (Cawood \& Howell, 1988). The frequency and severity of atrophy as well as four clinical 
aspects of bone quality and resorption are examined with respect to age within different segments of the jaw. Understanding the natural history of this disease could help to improve our knowledge about atrophy of the jaw, the final result of tooth loss, and is a prerequisite for the development of new treatment strategies. This study also provides additional new information for the interpretation of living conditions and lifestyles of historical populations (Alt, 1987; Vodanovic' et al., 2005; Meller et al., 2009).

\section{Material and methods}

\section{Avarian skeletal remains}

A large mediaeval cemetery with skeletal remains of an Avarian population was unearthed during archaeological excavations in the 11th district of Vienna, Austria. This Avarian cemetery of the 7th - 8th century A.D. consisted of 705 graves. In total, the skeletal remains of 755 individuals were collected.

263 jaw specimens of this sample met the inclusion criteria of 1) completion of dental development, i.e. presence of permanent dentition and 2) a sufficient state of preservation of the jaw allowing the evaluation of the features described hereinafter.

Estimation of age at death and determination of sex was based on osteological and dental development criteria, [according to the recommendations of Sarospatak (Ferembach et al., 1979)] and had previously been performed by Großschmidt (1990). Age at death was determined according to the degree of cranial suture synostosis, surface characteristics of the symphysis of the pubic bone and of the auricular surface of the ilium and the degree of tooth abrasion (White \& Folkens, 1999). The degenerative processes evaluated in this study, were not used to establish an age estimate and both factors are therefore independent of one another.

According to these data, the study sample was divided into three age groups of young (21-40 years), middle-aged (41-60 years) and old (61-80 years) individuals. Demographic data concerning age and sex distribution of the analysed population are presented in Table $\mathbf{1 .}$

\section{Methods}

Three investigators (WRL, ST, KMR), experienced in the analysis of degenerative alterations of the jaw, discussed and interpreted the variation and expression of signs of atrophy in the sample. The application of the classification systems employed in this study was standardized and calibrated until a consensus was reached. The practical evaluations and classifications however, were performed solely by one investigator (WRL) to avoid interobserver error. While undertaking these evaluations the investigator was blinded to age and sex of the individuals. The following features were macroscopically diagnosed under bright light.

\section{Classification of atrophy stages}

Based on the classification system of Nakamato (1968) six separate segments of the jaw were defined as depicted in Figure 1. Each segment of the 263 jaw specimens was assigned to one of the 6 stages of atrophy described by Atwood (1963) and Cawood and Howell (1988). (See Figure 2)

Stage 1 describes the physiological state of preextraction at which the tooth is still in the alveolar socket or the tooth is lost post mortem. Stage 2 is assigned to tooth loss immediately before death. There are slight osseous reactions of new bone formation within the alveolus. The alveolus is still in a good condition and the edges might be sharpened.

In stage 3 the alveolus is completely refilled with newly formed bone. The shape of the original alveolus is no 

longer identifiable and the top of the alveolar process finally becomes well-rounded due to first signs of resorption. However, there is no notable reduction in height.

In stage 4 the shape of the alveolar crest alters into a thin and sharp knife-edge; the body of the jaw is still adequate in height and width.

Stage 5: Further resorption leads to a low well-rounded ridge which is flat but already reduced in height and width; the alveolar process is lost.

Stage 6: Continuing excessive atrophy of the residual crest results in a depressed bone level, where even the basal bone shows signs of reduction.

\section{Exposed trabecular bone at the top of the residual ridge}

Atwood (1971) and Pietrokovski (1975) stated that in many individuals the cortical layer cannot close over the former alveolus and adjacent areas sufficiently due to degenerative and resorptive alterations of the alveolar crest. Accordingly, the residual crest exhibits trabecular bone, extending over the whole length of an edentulous ridge. (See Figure 3A)

Stage I describes the situation after tooth loss in which the alveolus is totally closed and the crest completely covered by cortical bone.

In stage II, the cortical layer of the alveolar crest is not closed, but discontinuous so that an area of exposed trabecular bone with a width of up to $2 \mathrm{~mm}$ is identifiable.

In stage III, the cortical layer of the crest is interrupted by even larger areas of exposed trabecular bone of more than $2 \mathrm{~mm}$ in width.

\section{Bony defects in the region of the former alveolus}

Due to poor or incomplete repair of the alveolus after tooth loss, bony defects such as trabecular spots and macroscopic perforations (Solar et al., 1998) might be observed on the crest of the residual ridge (Nakamato, 1968; Pietrokovski et al., 2007). (See Figure 3B)

As opposed to exposed trabecular bone, the occurrence of this feature is thought to be restricted to the area of the former alveolus (Neufeld, 1958; Lammie, 1960). However, Nakamoto (1968) doubted this limited extension of such defects since he could not detect a relation between the area of former alveolar sockets and the location of defects. To scrutinise this discrepancy and to check whether a discrimination of exposed trabecular bone and defects is expedient and useful, both features are separately assessed in this present study.

In stage I, no defects are present. Stage II characterises a residual alveolar crest with small defects. The cortical layer encircles little trabecular inclusions of e.g. flame-like or channel-like shape. In stage III, the observed irregularities at the cortical layer are increased in size.

\section{Concave depression of the alveolar crest}

In consequence of the loss of several adjacent teeth, the bone tissue in this edentulous space often breaks down. The wound area in this edentulous part of the jaw is too large, so that bone is not able to regenerate up to the height of the former alveolar crest resulting in a depressed level of the residual ridge. Towards the adjacent tooth (or teeth, if existent) the bone level maintains the original height of the alveolar process. So-called concave depressions can be observed at the distal end of the dentate arch (Pietrokovski, 1975) as well as in an edentulous space between remaining teeth.

A segment is classified as stage I if there is no concavity observed.

Stage II describes an edentulous ridge portion with a concave depression looking like a recess in the residual ridge. 


\section{Results}

\section{Frequency and severity of analysed features}

\subsection{Atrophy}

Atrophy in at least one segment was present in 120 of the 263 analysed specimens.

The frequency of occurrence of jaw atrophy (including the stage of recent, intravital tooth loss) in this population is presented in Figure $\mathbf{4}$ for the anterior and posterior segments of the mandible and the maxilla.

Three general trends concerning frequency and distribution of atrophy of the jaw are apparent:

1) Frequency and also severity of atrophy were lowest in the youngest age group (20-40 years) and increased significantly with advancing age. The occurrence of atrophy is highly correlated with age in all segments of the jaw $(\mathrm{p} \leq 0.001)$.

2) The mandible $(\mathrm{Md})$ tended to be worse affected than the maxilla $(\mathrm{Mx})$, independent of the position of the segment and the age group.

3) The posterior segments (post.) of both the mandible and the maxilla exhibited an increased frequency and also more severe stages of atrophy than the anterior segments (ant.) in all age groups.

Differences in the distribution of the 5 stages of atrophy, from postextraction state to a depressed level, in the 
analysed segments of all age groups are shown in Figure 5. Percentages of atrophy stages were calculated from affected segments only (atrophy stages 2 to 6), hereinafter referred to as $100 \%$.

In the youngest age group (20-40yrs), atrophy was negligibly rare in the anterior segments. In the posterior segments atrophy was slightly more frequent. In the older age groups (41-60yrs and 61-80yrs), a shift from the lower to the higher, more severe atrophy stages was identified. Atrophy stage 4, representing a residual ridge shaped like a knife-edge, was most frequent in anterior segments, particularly of the mandible. By contrast, in posterior segments, atrophy stage 5 , characterised by a reduced height of the ridge with a well-rounded crest, and stage 6, a depressed ridge level, were most frequent. Particularly in posterior segments of the mandible, atrophy showed two peaks, one at stage 2 (postextraction) and one at stage 5 (low well-rounded), whereas the stages in between were very rare.

In brief, the knife-edge shape was the predominant stage of atrophy in anterior segments. Stage 5, the low wellrounded ridge, and stage 6 , the depressed ridge, played a less prominent role in anterior segments than in | posterior segments, where atrophy appeared to attain more severe stages more rapidly with increasing age. Mandibulary posterior segments of old individuals seemed to be the most affected of all.

Fisher's exact tests showed a statistically significant relationship between age group and atrophy stage in anterior segments of the mandible (ant. Md: $\mathrm{p}=0.049$ ) and posterior segments of the maxilla (post. Mx: $\mathrm{p}=0.034$ ). In the other segments no significant correlation was detected (post. $\mathrm{Md}$ : $\mathrm{p}=0.095$; ant. $\mathrm{Mx}$ : $\mathrm{p}=0.974$ ).

\subsection{Exposed trabecular bone at the top of the residual ridge}

This feature was more frequent in the mandible than in the maxilla. Posterior segments were more severely and more often affected than anterior segments. Yet, frequency and extent of exposed trabecular bone increased only up to the middle-aged group and decreased again in the oldest age group. (See Table 2)

Due to the low rate of atrophy in anterior segments of the youngest age group (20-40yrs), the feature of exposed trabecular bone at the crest of the residual ridge was also very rare. In posterior segments, the rate of affection was higher with stage III (area of exposed trabecular bone $\geq 2 \mathrm{~mm}$ in width) being the predominant stage in young individuals. In the middle-aged group (41-60yrs), the prevalence of a discontinuous cortical layer increased in all segments, posterior segments again being worse affected by stage III. In old individuals (61-80yrs), the frequency of stage III decreased compared to the middle-aged group. In contrast, stage I, characterised by a closed cortical layer at the crest, became more frequent and even obtained its peak frequency in this age group. A significant correlation between age group and the occurrence of different stages of exposed trabecular bone was identified for the posterior segments of the mandible (post. Md: p=0.011) and the maxilla (post. Mx: $\mathrm{p}=0.010$ ), but not for anterior segments of either jaw (ant. Md: $\mathrm{p}=0.375$; ant. $\mathrm{Mx}: \mathrm{p}=1.000$ ).

\subsection{Bony defects at the crest of the residual ridge}

Bony defects occurred with a higher frequency in the mandible than in the maxilla. Posterior segments were more frequently affected than anterior segments. Similarly to atrophy, frequency increased with advanced age and reached a plateau in the middle-aged (41-60yrs) and old group (61-80yrs). Indeed, also the frequency of stage I (properly healed alveolus covered by a continuous cortical layer) was increased in old individuals. (See Table 2)

In detail, bony defects in the region of the former alveolus were very rare in anterior segments of young adults (20-40yrs), which is the result of low affection by atrophy. In posterior segments, the frequency of poorly healed alveoli was higher, showing a pronounced occurrence of small defects (stage II) in the posterior segment of mandible. The middle-aged group showed a notable increase of stage I in anterior segments and of stage III (large trabecular spots at the crest) in posterior segments. In old individuals stage III was mainly identified in 
posterior segments of the maxilla. In the other segments, the frequency of stage III decreased in favour of an increase of stage I, when compared to the middle-aged group.

Bony defects did not show a statistically significant correlation with age in any jaw segment (ant. Md: $\mathrm{p}=0.699$, post. Md: $\mathrm{p}=0.120$; ant. $\mathrm{Mx}: \mathrm{p}=0.312$, post. $\mathrm{Mx}: \mathrm{p}=0.218)$.

\subsection{Concave depression of the alveolar crest}

With advanced age, the frequency of concave depressions increased. In the mandible, concave depressions occurred more frequently than in the maxilla. Posterior segments were affected with a higher frequency than anterior segments. (See Table 3)

In anterior segments of young adults (20-40yrs), concave depressions were almost non-existent. In the middleaged group (41-60yrs), this feature occurred with a frequency of $14.3 \%$ in the anterior mandible and $22.2 \%$ in the anterior maxilla. In the oldest age group (61-8yrs), the anterior segments of the lower and the upper jaws were conversely affected with an increased frequency of $31.8 \%$ in mandibular segments and a decrease to $14.3 \%$ in maxillary segments.

In posterior segments, the frequency of concave depressions was increased compared to anterior segments in young and middle-aged individuals; the latter representing the most affected age group. Posterior segments of old individuals (61-8yrs) showed a decline in frequency.

This tendency was not pronounced enough to show a significant relationship between the occurrence of concave depressions and age in any segment (ant. Md: $\mathrm{p}=0.544$, post. $\mathrm{Md}$ : $\mathrm{p}=0.542$; ant. $\mathrm{Mx}$ : $\mathrm{p}=0.300$, post. $\mathrm{Mx}$ : $\mathrm{p}=0.431)$.

\subsection{Exposed mandibular canal}

An exposed mandibular canal (stage II) was a very rare feature. With increasing age its frequency rose slightly. In the middle-aged group (41-60yrs) $3(6.7 \%)$ and in old individuals $7(16.7 \%)$ posterior segments were affected by such signs of excessive resorption.

\section{Correlation of atrophy and concomitant features}

\subsection{Exposed trabecular bone \& atrophy}

In both the anterior and the posterior segments of the mandible, a statistically significant correlation between atrophy classes and the extent of exposed trabecular bone was identified (ant. Md: p=0.004; post. Md: p<0.001). The size of exposed trabecular bone areas seemed to decrease with the progress of atrophy in the mandible. (See Table 4)

A continuous cortical layer covering the former alveolus without exposed trabecular bone at the surface (stage I) was the predominant feature in anterior mandibular segments classified as atrophy class 4 (knife-edge ridge). In posterior segments, this feature increased with the progress of atrophy and reached the highest frequency in depressed residual ridge (atrophy stage 6).

Exposed trabecular bone of up to $2 \mathrm{~mm}$ in width (stage II) was most common in posterior segments classified as atrophy stage 5 and 6 . Exposed trabecular bone of more than $2 \mathrm{~mm}$ in widths (stage III) was most frequently observed in segments classified as atrophy stage 2 postextraction. At this atrophy stage, tooth loss did not date back very long; the alveolus already showed first signs of regeneration but the cortical layer had not closed completely over the trabecular area.

In the maxilla, there was no significant relationship between the dimensions of atrophy and exposed trabecular bone (ant. Mx: $\mathrm{p}=0.310$; post. $\mathrm{Mx}: \mathrm{p}=0.655$ ).

\subsection{Bony defects at the crest \& atrophy}




\section{Discussion}

Atrophy of the jawbone following tooth loss is a very common oral disease particularly in elderly people. Affected patients suffer not only from alterations of the anatomic structure of their jaw and loss of function but also from changes of the facial shape and psychological problems (Atwood, 1971) such as a reduced quality of life (Jokstad et al., 2000a; Jokstad et al., 2000b), feelings of shame, insecurity and decreased attractiveness (Trulsson et al., 2002). Thus, the major tasks of prosthetic or implant-supported treatment are, on the one hand, to restore the function including mastication (Şahin et al, 2002) and speech, and on the other hand, to preserve the appearance and well-being of the patient (Jokstad et al., 2000a; Jokstad et al., 2000b; Sutton et al., 2004; Heydecke et al., 2005; Pan et al., 2008; Fenlon \& Sherriff, 2008).

Despite these undoubtedly positive results of prosthetic treatment, there are diverging opinions as to whether or not there are severe side effects. Several studies have shown that in patients wearing dentures the reduction of the residual ridge was worse than in patients without dentures (Thoma, 1959; Campbell, 1960; Carlsson et al., 1969). As an explanatory concept, pressure atrophy is particularly plausible for ill-fitting dentures (Carlsson et al., 1969; Xie et al., 1997a). By contrast, atrophy was also described in patients without prosthetic treatment (Devlin \& Ferguson, 1991; Thoma, 1959) supporting the concept of disuse atrophy.

Atwood (Atwood, 1971; Atwood, 1973) assumed that three major groups of co-factors seem to influence the series of events from wound healing of the affected alveolus to resorption of the alveolar process. These are (1) anatomic structure of the jaw, the (2) biology of the individual (age, sex, hormonal balance etc.) and (3) mechanical factors such as force applied to the alveolar bone and the influence of prosthetic procedures.

Anatomy and biology of the patient are predetermined. Hence, one factor left to influence the inevitable progress of atrophy is prosthetics. Clinicians can select from a wide variety of prosthetic and surgical treatment options including traditional removable prosthesis, implant supported dentures, or a combination of both. However, the outcome of the chosen therapy is hardly predictable (Carlsson et al., 1969). For that reason, and to find the best individual solution for every patient, it is necessary to increase our knowledge about the preserving or destructive effect of prosthetic procedures. Due to the complex pathoaetiology of atrophy (Carlsson, 2004), the true, unbiased influence of prosthetic treatment is difficult to isolate from the broad spectrum of co-factors. Consequently, there is a growing demand for a purpose-made study design, someway comparable to a knockout experiment in mice. In a knockout study, the effect of a specific gene of unknown function is analysed by 
deactivating the gene. Thus, differences from the normal condition can be examined and the probable function of the gene can be inferred. In this present study, the influence of prosthetic treatment was "knocked out" by analysing an historical population that did not practice any kind of modern dentistry. By this means the natural course of disease could be studied excluding the mechanical factor of prosthetics.

Our results proved that atrophy of the jaw after tooth loss definitely does occur in a population without prosthetic treatment, which is in strong agreement with the concept of a multifactorial disease (Atwood, 1971). Furthermore, we could show that even without prosthetics the residual ridge underwent similar changes in height and shape as described by Atwood (1963) and Cawood and Howell (1988). As expected, old individuals were more frequently and worse affected than younger ones. This seems self-evident since tooth loss usually dates back further in old people's lives. Hence, atrophic processes had less time to proceed in individuals that died at an earlier age. In addition, with increasing age the loss of several teeth accumulates - a situation that might promote the development of advanced atrophy stages. The prevalence of postextraction segments increased in middle-aged individuals, possibly indicating that this age group is very susceptible to tooth loss.

Notable differences in rate and degree of atrophy were observed between the mandible and the maxilla as well as between anterior and posterior segments in all age groups, which might be the result of differences in anatomy. Posterior segments showed a higher frequency and degree of atrophy than anterior segments, which is in concordance with the fact that molars tend to be lost at an earlier age than anterior teeth. Hence, atrophy might develop in the posterior part of the jaw first and progress further (Ulm et al., 2009). Interestingly, in maxillary posterior segments the residual ridge seemed to skip atrophy stages 3 to 5 resulting rather directly in a depressed bone level (stage 6) in both older age groups. Accordingly, stages 3 to 5 seem to be shorter processes, so that the jaw does not remain long in these stages. By contrast, in the mandible the transition of stage 5 to stage 6 (depressed) took place with some time lag in the oldest group. This might indicate that in the initial phases of atrophy mandible offers more resistance to vertical resorption, probably due to the greater thickness of its cortical bone, than the maxilla. However, subsequently the mandible was more frequently and worse affected than the maxilla.

Several studies on denture-wearing patients have attributed the higher atrophy rate in the lower jaw to the smaller surface and the unfavourable shape of the mandibular ridge on which mechanical loads are applied to in edentulous patients (Tallgren, 1972; Tallgren et al., 1980; Bodic et al., 2005). By contrast, the maxilla is thought to resist loads of dentures more successfully, because of the larger supporting surface of the hard plate (Tallgren, 1972). In the present study, prosthetics cannot be held responsible for the higher degree of resorption of the lower jaw. That leads us back again to other factors that might be involved. It seems plausible that forces through chewing and swallowing are applied to the residual ridge also in non-denture wearers. Alterations in frequency, intensity and direction of such forces might lead to an imbalance of the neuromuscular stability (BudtzJörgensen, 1996; Kingsmill, 1999) and thus to an impaired activation of osteoblasts and osteoclasts, probably resulting in a discrepancy of resorption (Atwood, 1962). As recently shown by Rawlinson et al. (2009) also differences in gene expression of developmentally and/or functionally distinct skeletal sites play a role in their response to mechanical stimuli. The described differences in gene expression profiles between the skull vault and limb bones were attributed to cell (osteoblast) populations of distinct embryonic lineages. This developmental, "positional identity" of bone cells has been shown to determine cell activity and matrix characteristics probably leading to differences in their susceptibility to osteoporosis and adaptation to mechanical strain.

In anterior segments of either jaw, a knife-edge shape of the residual ridge was predominant. This stage 4 is particularly problematic for implantology since the width of the crest is insufficient for the insertion of endosseous implants. Heights of $6 \mathrm{~mm}$ and $10 \mathrm{~mm}$ as well as widths of $6 \mathrm{~mm}$ and $5 \mathrm{~mm}$ are regarded as minimum dimensions for successful implantation in the maxilla and the mandible, respectively (Neukam \& Kloss, 2001). 
Also well-rounded ridges with reduced height and ridges with a depressed bone level (stage 5 and 6), which are predominant in posterior segments, do not meet the standard criteria for implantation and require pre-treatment complex surgical procedures, such as the removal of the thin bone structure (Nishimura \& Atwood, 1994) or/and alveolar ridge augmentation by bone graft techniques (Ulm et al., 1995; Coulthard et al., 2002; Bodic et al., 2005). Even in the most recent systematic reviews on the subject (Esposito et al., 2006; Aghaloo \& Moy, 2007; Rocchietta et al., 2008), there are no indications which frequencies of cases that necessitate bone augmentation procedures a surgeon has to expect. According to the results of the present study, implantologists might figure that up to $75 \%$ of elderly patients require some kind of surgical pre-treatment (depending on the region of the jaw). A comparison with modern populations is hardly possible since data on prevalence are very rare and information about the sample is mostly lacking. Denissen et al. (1993) analysed a sample of 61 middle-aged patients (40-65 years of age) treated with prostheses. $51.6 \%$ of these dried edentulous mandibles showed a knifeedge shape (atrophy stage 4) compareable to a prevalence of $50 \%$ in ant. Md. segments of middle-aged individuals of this present study. Al-Faleh (2009) found a similar prevalence of $46.5 \%$ in an inhomogeneous sample of 30 17-67 year old patients. Pietrokovski et al. (2007) studied a sample of 123 human edentulous dried skulls of unknown age, sex and treatment and described $38 \%$ of these maxillary and mandibulary ridges to be knife-edged.

Another aspect of clinical relevance is the bone quality of the cortical layer covering the crest of the residual ridge. In fact, a large amount of continuous cortical bone provides good primary stability of the implant and hence decreases the risk of implant failure (Rabel et al., 2007). Alterations in cortical layer, such as areas of exposed trabecular bone and osseous defects, might have negative implications for the insertion of endosseous implants (Pietrokovski et al., 2007). A closed cortical layer offers more resistance to the bur used than does a crest with macroscopic openings and exposed trabeculae. Thus, there is a risk of overdosing the force at the transition from the outer surface to the trabecular compartment when drilling a hole for the implant (Pietrokovski, 1975).

According to our observations, the differentiation based on the localisation at the crest (Atwood, 1971; Pietrokovski, 1975; Neufeld, 1958; Lammie, 1960) was not unequivocal, so that in many cases trabecular spots were classified as both exposed trabecular bone and bony defects.

Yet, the results demonstrated that exposed trabecular bone and defects at the crest do occur in absence of prosthetic treatment. Also, an exposed mandibular canal was detected in a few individuals as a result of excessive atrophy. In the analysed population, the prevalence of an exposed mandibular canal was $6.7 \%$ for $41-$ 60 year-old individuals and $16.7 \%$ for individuals over 61 years of age. Xie et al. (1997b) reported an even higher prevalence of $27 \%$ in a sample of 128 76-86 year old patients. The exact localisation of the mandibular canal is essential to know for an implantologist when planning and inserting endosseous implants in the atrophic mandible (Ulm et al., 1993; Lindh et al., 1995), since an injury would implicate neurosensory damage or even loss of sensation (Ulm et al., 1993).

In this study, some limitations were encountered. Since only individuals with a sufficient state of preservation were included, the sample might be biased to some extent (Meinl, 2009). Due to the lack of information about the time point of tooth loss and hence of the duration being (partly) edentulous, no conclusions about the rate of atrophy (i.e. the amount of bone being resorbed) per time unit could be drawn. The observed features within the jawbone mirror only the conditions at time of death. The role of osteoporosis in the development and progression of jaw atrophy is still controversially discussed (Hildebolt, 1997; Bollen et al., 2004; Felton, 2009; Yüzügüllü et al., 2009). However, due to the large sample size of 263 jaw specimens it was economically not possible to study systemic bone disorders such as osteopenia and osteoporosis by means of x-rays or DEXA. Several studies reported that osteoporosis might promote ridge resorption (Bays \& Weinstein, 1982; Kribbs et al., 1983; Hirai et al., 1993) and tooth loss (Nicopoulou-Karayianni et al., 2009) whilst others failed to demonstrate a correlation 
(Klemetti et al. 1993a; Klemetti et al. 1993b; Bollen et al., 2004). Devlin \& Horner (2007) state that age-related bone loss of the jaw resulting in cortical porosity and a reduced BMD and BMC (Hildebolt, 1997) has to be clearly distinguished from external alterations of the mandibular alveolar process due to tooth loss. Moreover, a recent review of Slagter et al. (2008) reported no more than a minimal evidence for a relation between osteoporosis and jaw atrophy. Future studies evaluating radiographic data of atrophic jaws would be of great value to shed light onto this issue. So far, most published studies dealing with atrophy after tooth loss did not meet modern scientific standards, mainly being written in a descriptive style, and lacking information on the sample. Moreover, they had been limited to the assessment of single features of this complex oral disease. Here we present a study analysing concomitant features described in literature and questioning/challenging the consistency and applicability of the classification system. The strength of this current study lies in the analysis of the natural history of atrophy in a large sample of a mediaeval population excluding the influence of prosthetic treatment.

Results demonstrated that atrophy evidently did occur in the absence of prosthetics and followed the pattern of resorption described for modern populations (Atwood, 1963; Cawood \& Howell, 1988). Concomitant features, i.e. exposed trabecular bone, osseous defects, concave depression and exposed mandibular nerve, were present and often correlated with the occurrence of advanced atrophy stages. A differentiation of exposed trabecular bone and bony defects at the crest of the ridge appears not to be useful since they were hardly distinguishable and their developmental mechanisms might overlap to some extent. Yet, their presence might be of clinical relevance for the planning and realisation of dental implants and prostheses.

Above all, our findings present basic information about the pathology of jaw atrophy and provide a deeper insight into the structural characteristics of this common oral disease. Further research in this field is required to study the effect and relative weights of other factors involved in this multifactorial process. 


\section{Conclusions}

1. Atrophy of the jawbone following tooth loss is a multifactorial disease that is not attributable to prosthetics alone, since its occurrence is observed in a population without modern prosthetic treatment.

2. The residual ridge undergoes a series of changes in shape and height following the pattern of resorption described for modern populations. The severity of these alterations is associated with the age of the individual and the region within the jaw.

3. Atrophy is frequently related to structural alterations of the covering cortical layer which all together might have clinical relevance for planning and realisation of dental implants and prostheses. 


\title{
Acknowledgements
}

The authors thank Martina Traindl-Prohazka of the Department of Anthropology, University of Vienna, for providing the skeletal remains, stored in the Department of Anthropology, University of Vienna, Austria. We express gratitude to Karl Großschmidt for providing his data on sex and age determination of the study sample. Thanks are also due to Robert Hütter of the Department of Oral Surgery, Medical University of Vienna, Austria for his technical support in taking photographs and creating figures.

\section{Conflict of interest}

None declared.

\begin{abstract}
Authors Contributions
KMR was the primary author of the manuscript, was involved in the development of standardised and calibrated evaluation criteria, analysed and interpreted the results, reviewed literature and submitted the manuscript. CDH performed the statistical analyses and was involved in the interpretation of the results. WRL participated in study design, establishment of methods and performed practical evaluation and classification, being blinded to individuals' age and sex. CU and GW supervised the progress of the project, reviewed the manuscript critically and helped to finalise the manuscript. GW also provided funding for the study. ST designed and planned the study and monitored the progress of the project. He was also involved in the development of standardised and calibrated of evaluation criteria and in data interpretation and helped to prepare the paper.

All authors have contributed to, seen and approved the manuscript.
\end{abstract}




\section{References}

Aghaloo TL, Moy PK (2007). Which hard tissue augmentation techniques are the most successful in furnishing bony support for implant placement? International Journal of Oral and Maxillofacial Implants 22 (Suppl): 4970 .

Al-Faleh W (2009) A radiographic study on the prevalence of knife-edge residual alveolar ridge at proposed dental implant sites. Saudi Detal Journal 21:23-7.

Alt K (1987). Zahnerkrankungen sind schon tausende von Jahren alt. Zahnärztliche Mittelungen 77: $2274-87$.

Atwood DA (1962). Some clinical factors related to rate of resorption of residual ridges. The Journal of Prosthetic Dentistry 12: 441-50.

Atwood DA (1963). Postextraction changes in the adult mandible as illustrated by microradiographs of midsagittal sections and cephalometric roentgenograms. The Journal of Prosthetic Dentistry 13: 810-24.

Atwood DA (1971). Reduction of Residual Rides: A Major Oral Disease Entity. The Journal of Prosthetic Dentistry 26: 266-79.

Atwood DA (1973). Reduction of residual ridges in the partially edentulous patient. Dental Clinics of North America 17: 747-54.

Atwood DA (1979). Bone Loss of Edentulous Alveolar Ridges. Journal of Periodontology 50: 11-21.

Bays RA, Weinstein RS (1982) Systemic bone disease in patients with mandibular atrophy. J Oral Maxillofac Surg 40:270-2.

Bodic F, Hamel L, Lerouxel E, Baslé MF, Chappard D (2005). Bone Loss and Teeth - Review. Joint Bone Spine. 72: 215-21.

Bollen AM, Taguchi A, Hujoel PP, Hollender LG (2004) Number of teeth and residual alveolar ridge height in subjects with a history of self-reported osteoporotic fractures. Osteoporos Int 15:970-4.

Bras J (1990). Mandibular Atrophy and Metabolic Bone Loss. International Dental Journal 40: 298-302.

Budtz-Jörgensen E (1996). Restoration of the partially edentulous mouth - a comparison of overdentures, removable partial dentures, fixed partial dentures and implant treatment. Journal of Dentistry 24: 237-44.

Campbell RL (1960). A comparative study of the resorption of the alveolar ridges in denture-wearers and nondenture-wearers. Journal of the American Dental Association 60: 143-53.

Carlsson GE, Ragnarson N, Astrand P (1969). Changes in height of the alveolar process in edentulous segments. II. A longitudinal clinical and radiographic study over 5 years of full upper denture patients with residual lower anteriors. Swedish Dental Journal 62: 125-36.

Carlsson GE (2004). Responses of jawbone to pressure. Gerodontology 21: 65-70.

Cawood JI, Howell RA (1988). A Classification of the Edentulous Jaws. International Journal of Oral and Maxillofacial Surgery 17: 232-6.

Coulthard P, Esposito M, Worthington HV, Jokstad A (2002). Interventions for replacing missing teeth: preprosthetic surgery versus dental implants. Cochrane Database of Systematic Reviews; 4. Art. No.: CD003604. DOI: 10.1002/14651858.CD003604.

Denissen HW, Kalk W, Veldhuis HA, van Waas MA (1993). Anatomic Considerations for Preventive Implantation. The International Journal of Oral and Maxillofacial Implants 8: 191-6.

Devlin H \& Ferguson MW (1991). Alveolar Ridge Resorption and Mandibular Atrophy - A Review of the Role of Local and Systemic Factors. British Dental Journal 170: 101-4.

Devlin H, Horner K (2007) A study to assess the relative influence of age and edentulousness upon mandibular bone mineral density in female subjects. Oral Surg Oral Med Oral Pathol Oral Radiol Endod 104:117-21.

Esposito M, Grusovin MG, Coulthard P, Worthington HV (2006). The efficacy of various bone augmentation 15 
procedures for dental implants: a Cochrane systematic review of randomized controlled clinical trials. International Journal of Oral and Maxillofacial Implants. 2: 696-710.

Felton DA (2009) Edentulism and comorbid factors. J Prosthodont 18:88-96.

Fenlon MR, Sherriff M (2008). An investigation of factors influencing patients' satisfaction with new complete dentures using structural equation modelling. Journal of Dentistry 36: 427-34.

Ferembach D, Schwidetzky I, Stloukal M (1979). Empfehlungen für die Alters- und Geschlechtsdiagnose am Skelett. Homo 30: 1-32.

Frost HM (2003). Bone's Mechanostat: A 2003 Update. Anatomic Record, Part A: Discoveries in Molecular, Cellular and Evolutionary Biology 275: 1081-101.

Großschmidt K (1990). Paläopathologische Untersuchnungen an den menschlichen Skeletten des awarenzeitlichen Gräberfeldes Csokorgasse in Wien Simmering. PhD [dissertation]. University of Vienna.

Gruber H, Solar P, Ulm C (1993). Anatomie und atrophiebedingte Veränderungen der Kieferknochen. In: Watzek G, ed. Enossale Implantationen in der oralen Chirurgie. Berlin: Quintessenz. p 29-62.

Heydecke G, Thomason JM, Lund JP, Feine JS (2005). The impact of conventional and implant supported prostheses on social and sexual activities in edentulous adults: Results from a randomized trial 2 months after treatment. Journal of Dentistry 33: 649-57.

Hildebolt CF (1997) Osteoporosis and oral bone loss. Dentomaxillofac Radiol 26:3-15.

Hirai T, Ishijima T, Hashikawa Y, et al. (1993) Osteoporosis and reduction of residual ridge in edentulous patients. J Prosthet Dent 69:49-56.

Jokstad A, Carr A, Esposito M, Coulthard P, Worthington HV (2002a). Interventions for replacing missing teeth: partially absent dentition (Protocol). Cochrane Database of Systematic Reviews; 3. Art. No.: CD003814. DOI: 10.1002/14651858.CD003814.

Jokstad A, Carr A, Esposito M, Coulthard P, Worthington HV (2002b). Interventions for replacing missing teeth: totally absent dentition (Protocol). Cochrane Database of Systematic Reviews; 2. Art. No.: CD003810. DOI: 10.1002/14651858.CD003810.

Kingsmill VJ (1999). Post-extraction remodeling of the adult mandible. Critical Reviews in Oral Biology and Medicine 10: 384-404.

Klemetti E, Vainio P, Lassila V, Alhava E (1993a) Trabecular bone mineral density in the mandible and alveolar height in post-menopausal women. Scand J Dent Res 101:166-70.

Klemetti E, Vainio P, Lassila V, et al. (1993b) Cortical bone mineral density in the mandible and osteoporosis status in postmenopausal women. Scand J Dent Res 101:219-23.

Kordatzis K, Wright PS, Meijer HJ (2003). Posterior Mandibular Residual Ridge Resorption in Patients with Conventional Dentures and Implant Overdentures. The International Journal of Oral and Maxillofacial Implants 18: 447-52.

Kribbs PJ, Smith DE, Chesnut CH III (1983) Oral findings in osteoporosis. Part II: Relationship between residual ridge and alveolar bone resorption and generalized skeletal osteopenia. J Prosthet Dent 50:719-24.

Lammie GA (1960). The Reduction of the Edentulous Ridges. The Journal of Prosthetic Dentistry 10: 605-11. Lindh C, Petersson A, Klinge B (1995). Measurements of distances related to the mandibular canal in radiographs. Clinical Oral Implants Research 6: 96-103.

Meinl A, Rottensteiner GM, Huber CD, Tangl S, Watzak G, Watzek G (2009). Caries frequency and distribution in an early medieval Avar population from Austria. Oral Dis [Eupub ahead of print].

Meller C, Urzua I, Moncada G, von Ohle C (2009). Prevalence of oral pathologic findings in an ancient preColumbian archeological site in the Atacama Desert. Oral Dis 15: 287-294.

Nakamato RY (1968). Bony Defects on the Crest of the Residual Alveolar Ridge. The Journal of Prosthetic 


\begin{abstract}
Dentistry 19: 111-8.
\end{abstract}
Neufeld JO (1958). Changes in the Trabecular Pattern of the Mandible Following the Loss of Teeth The Journal of Prosthetic Dentistry 8: 685-97.

Neukam FW, Kloss FR (2001). Compromised jawbone quantity and its influence on oral implant placement. In: Zarb G, Lekholm U, Albrektsson T, Tenenbaum H, ed. Aging, Osteoporosis and dental implants. Chicago: Quintessence. p85-97.

Nicopoulou-Karayianni K, Tzoutzoukos P, Mitsea A, Karayiannis A, Tsiklakis K, Jacobs R, Lindh C, van der Stelt P, Allen P, Graham J, Horner K, Devlin H, Pavitt S, Yuan J (2009). Tooth loss and osteoporosis: the OSTEODENT Study. J Clin Periodontol 36:190-7.

Nishimura I, Atwood DA (1994). Knife-edge Residual Ridges: A Clinical Report. The Journal of Prosthetic Dentistry 71: 231-4.

Pan S, Awad M, Thomason JM, Dufresne E, Kobayashi T, Kimoto S, Wollin SD, Feine JS (2008). Sex differences in denture satisfaction. Journal of Dentistry 36: 301-8.

Pietrokovski J (1975). The Bony Residual Ridge in Man. The Journal of Prosthetic Dentistry 34: 456-62.

Pietrokovski J, Starinsky R, Arensburg B, Kaffe I (2007). Morphologic Characteristics of Bony Edentulous Jaws. Journal of Prosthodontics 16: 141-7.

Rabel A, Köhler SG, Schmidt-Westhausen AM (2007). Clinical study on the Primary Stability of Two Dental Implant Systems with Resonance Frequency Analysis. Clinical Oral Investigations 11: 257-65.

Rawlinson SC, McKay IJ, Ghuman M, Wellmann C, Ryan P, Prajaneh S, Zaman G, Hughes FJ, Kingsmill VJ (2009). Adult rat bones maintain distinct regionalized expression of markers associated with their development. PLoS One 4:e8358.

Rocchietta I, Fontana F, Simion M (2008). Clinical outcomes of vertical bone augmentation to enable dental implant placement: a systematic review. Journal of Clinical Periodontology 35: 203-15.

Şahin S, Çehreli MC, Yalçin E (2002). The influence of functional forces on the biomechanics of implantsupported prostheses - a review. Journal of Dentistry 30: 271-82.

Sennerby L, Carlsson GE, Bergman B, Warfvinge J (1988). Mandibular Bone Resorption in Patients Treated With Tissue-Integrated Prostheses and in Complete Denture-Wearers. Acta Odontologica Scandinavica 46: 13540 .

Slagter KW, Raghoebar GM, Vissink A (2008) Osteoporosis and edentulous jaws. Int J Prosthodont 21:19-26.

Solar P, Aro G, Ulm C, Bernhart T (1998). Die Auswirkungen des Zahnverlustes auf die Anatomie der Maxilla. Schweizer Monatsschrift für Zahnmediziner 108: 871-5.

Sutton DN, Lewis BRK, Patel M, Cawood JI (2004). Changes in Facial Form Relative to Progressive Atrophy of the Edentulous Jaws. International Journal of Oral and Maxillofacial Surgery 33: 676-82.

Tallgren A (1972). The Continuing Reduction of the Residual Alveolar Ridges in Complete Denture Wearers: A Mixed-Longitudinal Study Covering 25 years. The Journal of Prosthetic Dentistry 27: 120-32.

Tallgren A, Lang BR, Walker GF, Ash MM Jr (1980). Roentgen Cephalometric Analysis of the Ridge Resorption and Changes in Jaw and Occlusal Relationships in Immediate Complete Denture Wearers. Journal of Oral Rehabilitation 7: 77-94.

Thoma KH (1959). Progressive Atrophie des Unterkiefers und ihre Behandlung. Deutsche Zahn-, Mund- und Kieferheilkunde 31: 248-61.

Trulsson U, Engstrand P, Berggren U, Nannmark U, Branemark P-I (2002). Edentulousness and Oral Rehabilitation: Experiences from the Patients' perspective. European Journal of Oral Sciences 110: 417-24. Ulm C, Pechmann U, Ertl L, Gruber H, Solar P, Matejka M (1989). Anatomische Untersuchungen an der atrophen Mandibula. Teil 1. Die Lage des Canalis mandibulae im atrophen Unterkiefer. Zeitschrift für Stomatologie 86: 491-503. 
Ulm CW, Solar P, Blahout R, Matejka M, Watzek G, Gruber H (1993). Location of the mandibular canal within the atrophic mandible. British Journal of Oral and Maxillofacial Surgery 31: 370-5.

Ulm CW, Solar P, Gsellmann B, Matejka M, Watzek G (1995). The Edentulous Maxillary Alveolar Process in the Region of the Maxillary Sinus - A Study of Physical Dimensions. International Journal of Oral and Maxillofacial Surgery 24: 279-82.

Ulm CW., Kneissel M, Hahn M, Solar P, Matejka M, Donath K (1997). Characteristics of the Cancellous Bone of Edentulous Mandibles. Clinical Oral Implants Research 8: 125-30.

Ulm C, Tepper G, Blahout R, Rausch-Fan X, Hienz S, Matejka M (2009). Characteristic features of trabecular bone in edentulous mandibles. Clinical Oral Implants Research 20: 594-600.

Vodanovic' M, Brikic' H, Salus M, Demo Z (2005). The Frequency and Distribution of Caries in the Mediaeval Population of Bijelo Brdo in Croatia (10th-11th Century). Archives of Oral Biology 50: 669-80.

Watt ME, Lunt DA, Gilmour WH (1997). Caries Prevalence in the Permanent Dentition of a Mediaeval Population from the South-West of Scottland. Archives of Oral Biology 42: 601-20.

White TD, Folkens PA (1999). Human Osteology. Oxford: Elsevier Ltd.

Wolff J (1892). The Law of Bone Remodeling. (English translation of Wolff's Das Gesetz der Transformation der Knochen by Maquet P. \& Furlong R. in 1986) Berlin: Springer.

Xie Q, Närhi TO, Nevalainen JM, Wolf J, Ainamo A (1997a). Oral Status and Prosthetic Factors Related to Residual Ridge Resorption in Elderly Subjects. Acta Odontologica Scandinavica 55: 306-13.

Xie Q, Wolf J, Tilvis R, Ainamo A (1997b). Resorption of mandibular canal wall in the edentulous aged population. J Prosthet Dent 77:596-600.

Yüzügüllü B, Gulsahi A, Imirzalioglu P (2009) Radiomorphometric indices and their relation to alveolar bone loss in completely edentulous Turkish patients: A retrospective study. J Prosth Dent 101:160-5. 
Table 2: Frequency distribution of the features exposed trabecular bone and bony defects stages I to III in the jaw segments of young (20-40yrs), middle-aged (41-60yrs) and old individuals (61-80yrs).

\begin{tabular}{|c|c|c|c|c|c|c|c|c|c|c|c|c|c|c|c|c|c|c|}
\hline & \multirow{3}{*}{$\begin{array}{l}\text { Trab. } \\
\text { bone }\end{array}$} & \multicolumn{4}{|c|}{ Mandible } & \multicolumn{4}{|c|}{ Maxilla } & \multirow{3}{*}{ Defects } & \multicolumn{4}{|c|}{ Mandible } & \multicolumn{4}{|c|}{ Maxilla } \\
\hline & & \multicolumn{2}{|c|}{ anterior } & \multicolumn{2}{|c|}{ posterior } & \multicolumn{2}{|c|}{ anterior } & \multicolumn{2}{|c|}{ posterior } & & \multicolumn{2}{|c|}{ anterior } & \multicolumn{2}{|c|}{ posterior } & \multicolumn{2}{|c|}{ anterior } & \multicolumn{2}{|c|}{ posterior } \\
\hline & & $\mathrm{N}$ & $\%$ & $\mathrm{~N}$ & $\%$ & $\mathrm{~N}$ & $\%$ & $\mathrm{~N}$ & $\%$ & & $\mathrm{~N}$ & $\%$ & $\mathrm{~N}$ & $\%$ & $\mathrm{~N}$ & $\%$ & $\mathrm{~N}$ & $\%$ \\
\hline \multirow{4}{*}{ 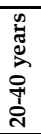 } & I & 0 & $0 \%$ & 5 & $26.3 \%$ & 0 & $0 \%$ & 4 & $28.6 \%$ & I & 1 & $33.3 \%$ & 3 & $15.8 \%$ & 0 & $0 \%$ & 7 & $50 \%$ \\
\hline & II & 1 & $50 \%$ & 4 & $21.1 \%$ & 1 & $50 \%$ & 0 & $0 \%$ & II & 2 & $66.7 \%$ & 13 & $68.4 \%$ & 1 & $100 \%$ & 3 & $21.4 \%$ \\
\hline & III & 1 & $50 \%$ & 10 & $52.6 \%$ & 1 & $50 \%$ & 10 & $71.4 \%$ & III & 0 & $0 \%$ & 3 & $15.8 \%$ & 0 & $0 \%$ & 4 & $28.6 \%$ \\
\hline & Total & 2 & $100 \%$ & 19 & $100 \%$ & 2 & $100 \%$ & 14 & $100 \%$ & Total & 3 & $100 \%$ & 19 & $100 \%$ & 1 & $100 \%$ & 14 & $100 \%$ \\
\hline \multirow{4}{*}{ 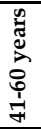 } & I & 3 & $21.4 \%$ & 10 & $22.2 \%$ & 2 & $22.2 \%$ & 1 & $3.4 \%$ & I & 7 & $50 \%$ & 11 & $24.4 \%$ & 6 & $66.7 \%$ & 11 & $37.9 \%$ \\
\hline & II & 7 & $50 \%$ & 8 & $17.8 \%$ & 2 & $22.2 \%$ & 1 & $3.4 \%$ & II & 7 & $50 \%$ & 17 & $37.8 \%$ & 3 & $33.3 \%$ & 4 & $13.8 \%$ \\
\hline & III & 4 & $28.6 \%$ & 27 & $60 \%$ & 5 & $55.6 \%$ & 27 & $33.1 \%$ & III & 0 & $0 \%$ & 17 & $37.8 \%$ & 0 & $0 \%$ & 14 & $48.3 \%$ \\
\hline & Total & 14 & $100 \%$ & 45 & $100 \%$ & 9 & $100 \%$ & 29 & $100 \%$ & Total & 14 & $100 \%$ & 45 & $100 \%$ & 9 & $100 \%$ & 29 & $100 \%$ \\
\hline \multirow{4}{*}{ 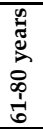 } & I & 7 & $31.8 \%$ & 23 & $54.8 \%$ & 4 & $30.8 \%$ & 6 & $25 \%$ & I & 9 & $40.9 \%$ & 15 & $35.7 \%$ & 11 & $78.6 \%$ & 4 & $17.4 \%$ \\
\hline & II & 13 & $59.1 \%$ & 8 & $19 \%$ & 3 & $23.1 \%$ & 4 & $16.7 \%$ & II & 10 & $45.5 \%$ & 16 & $38.1 \%$ & 3 & $21.4 \%$ & 6 & $26.1 \%$ \\
\hline & III & 2 & $9.1 \%$ & 11 & $26.2 \%$ & 6 & $46.2 \%$ & 14 & $58.3 \%$ & III & 3 & $13.6 \%$ & 11 & $26.2 \%$ & 0 & $0 \%$ & 13 & $56.5 \%$ \\
\hline & Total & 22 & $100.0 \%$ & 42 & $100 \%$ & 13 & $100 \%$ & 24 & $100 \%$ & Total & 22 & $100.0 \%$ & 42 & $100 \%$ & 14 & $100 \%$ & 23 & $100 \%$ \\
\hline
\end{tabular}

Trabecular bone: Stage I=closed cortical layer, stage II=exposed trabecular bone $\leq 2 \mathrm{~mm}$ in width, stage III $=$ exposed trabecular bone $\geq 2 \mathrm{~mm}$ in width.

Defects: Stage I=no defects, stage $\mathrm{II}=$ small defects, stage $\mathrm{III}=$ large defects.

Table 3: Frequency distribution of the features concave depression stages I and II in the jaw segments of young (20-40yrs), middle-aged (41-60yrs) and old individuals (61-80yrs).

\begin{tabular}{|c|c|c|c|c|c|c|c|c|c|}
\hline & \multirow{3}{*}{ Concavity } & \multicolumn{4}{|c|}{ Mandible } & \multicolumn{4}{|c|}{ Maxilla } \\
\hline & & \multicolumn{2}{|c|}{ anterior } & \multicolumn{2}{|c|}{ posterior } & \multicolumn{2}{|c|}{ anterior } & \multicolumn{2}{|c|}{ posterior } \\
\hline & & $\mathrm{N}$ & $\%$ & $\mathrm{~N}$ & $\%$ & $\mathrm{~N}$ & $\%$ & $\mathrm{~N}$ & $\%$ \\
\hline \multirow{3}{*}{ 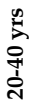 } & I & 2 & $100 \%$ & 9 & $47.4 \%$ & 0 & $0 \%$ & 8 & $57.1 \%$ \\
\hline & II & 0 & $0 \%$ & 10 & $52.6 \%$ & 1 & $100 \%$ & 6 & $42.9 \%$ \\
\hline & Total & 2 & $100 \%$ & 19 & $100 \%$ & 1 & $100 \%$ & 14 & $100 \%$ \\
\hline \multirow{3}{*}{$\begin{array}{l}\infty \\
5 \\
8 \\
0 \\
\frac{1}{7}\end{array}$} & I & 12 & $85.7 \%$ & 15 & $33.3 \%$ & 7 & $77.8 \%$ & 11 & $37.9 \%$ \\
\hline & II & 2 & $14.3 \%$ & 30 & $66.7 \%$ & 2 & $22.2 \%$ & 18 & $62.1 \%$ \\
\hline & Total & 14 & $100 \%$ & 45 & $100 \%$ & 9 & $100 \%$ & 29 & $100 \%$ \\
\hline \multirow{3}{*}{ 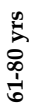 } & I & 15 & $68.2 \%$ & 15 & $35.7 \%$ & 12 & $85.7 \%$ & 12 & $52.2 \%$ \\
\hline & II & 7 & $31.8 \%$ & 27 & $64.3 \%$ & 2 & $14.3 \%$ & 11 & $47.8 \%$ \\
\hline & Total & 22 & $100.0 \%$ & 42 & $100 \%$ & 14 & $100 \%$ & 23 & $100 \%$ \\
\hline
\end{tabular}


Table 4: Cross tabulation demonstrating the interrelationship between atrophy stages and the occurrence of different degrees of exposed trabecular bone at the crest of the residual ridge. 


\section{Legends to Illustrations}

Figure 1: Segments of the jaw according to the classification system of Nakamato (1968). Mandible: SEG 1 (anterior), SEG 2 / SEG 3 (posterior, right/left). Red arrowheads indicate mental foramina, separating anterior from posterior segments; Maxilla: SEG 4 (anterior): between the two canines, SEG 5 / SEG 6 (posterior, right/left): between the $1^{\text {st }}$ premolar and the tuberosity at the distal end of the alveolar arch. Red arrowheads indicate borderline between canines and $1^{\text {st }}$ premolars.

Figure 2: Classification system of six atrophy stages in the maxilla (A) and the mandible (B) according to Atwood (1963) and Cawood and Howell (1988). Atrophy stage 1: preextraction, stage 2: postextraction, stage 3: high well-rounded ridge, stage 4: knife-edge shaped ridge, stage 5: low well-rounded ridge, stage 6: depressed bone level.

Figure 3: Photographs of two mandibular (right) posterior segments illustrating the differences between the features exposed trabecular bone and bony defects. (A) Area of exposed trabecular bone at the crest of the residual ridge (small black arrowheads). (B) Bony defects at the crest of the residual ridge (black arrowheads).

Figure 4: Prevalence of atrophy (stages 2 to 6 ) and of the non-affected state before tooth loss (stage 1) in anterior and posterior segments of the mandible and the maxilla. Jaw segments: le.=left, ri=right, ant.$=$ anterior, post.$=$ posterior, $\mathrm{Md} .=$ mandible, $\mathrm{Mx} .=$ maxilla .

Figure 5: Frequency distribution of the atrophy stages 2 to 6 (postextraction to depressed bone level) in the jaw segments of young (A), middle-aged (B) and old individuals (C). Due to the low frequency of atrophy in young individuals data were presented as absolute values instead of percents. By this means, the total increase of affected segments is evident. Atrophy stages: $2=$ postextraction, $3=$ high well-rounded, $4=k n i f e-e d g e, 5=l o w$ wellrounded, $6=$ depressed . Jaw segments: ant.=anterior, post. $=$ posterior, $\mathrm{Md} .=$ mandible, $\mathrm{Mx} .=$ maxilla . 

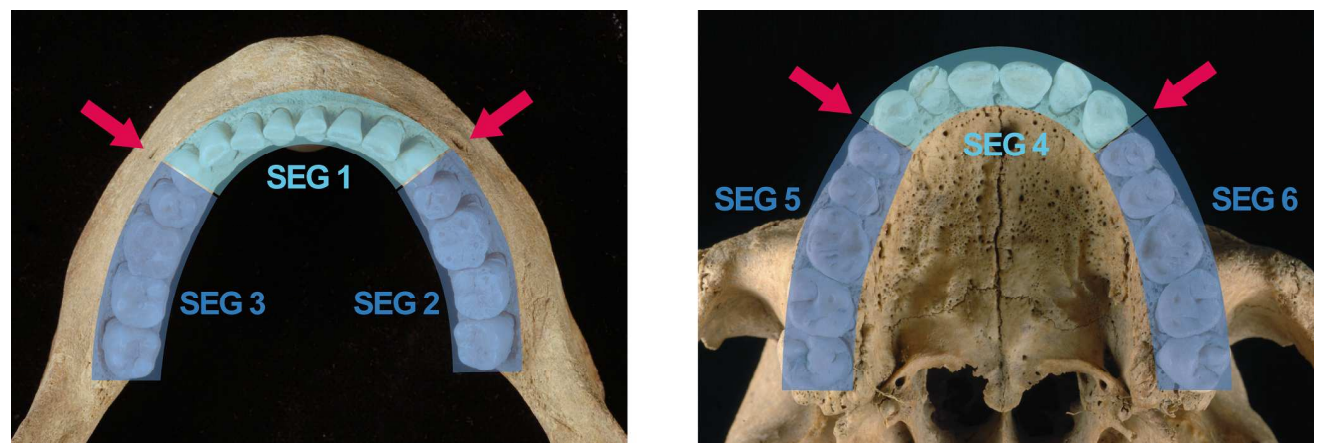

Figure 1: Segments of the jaw according to the classification system of Nakamato (1968). Mandible: SEG 1 (anterior), SEG 2 / SEG 3 (posterior, right/left), red arrowheads indicate mental foramina, separating anterior from posterior segments; Maxilla: SEG 4 (anterior), SEG 5 / SEG 6 (posterior, right/left), red arrowheads indicate borderline between canines and 1st premolars. $175 \times 58 \mathrm{~mm}(600 \times 600 \mathrm{DPI})$ 

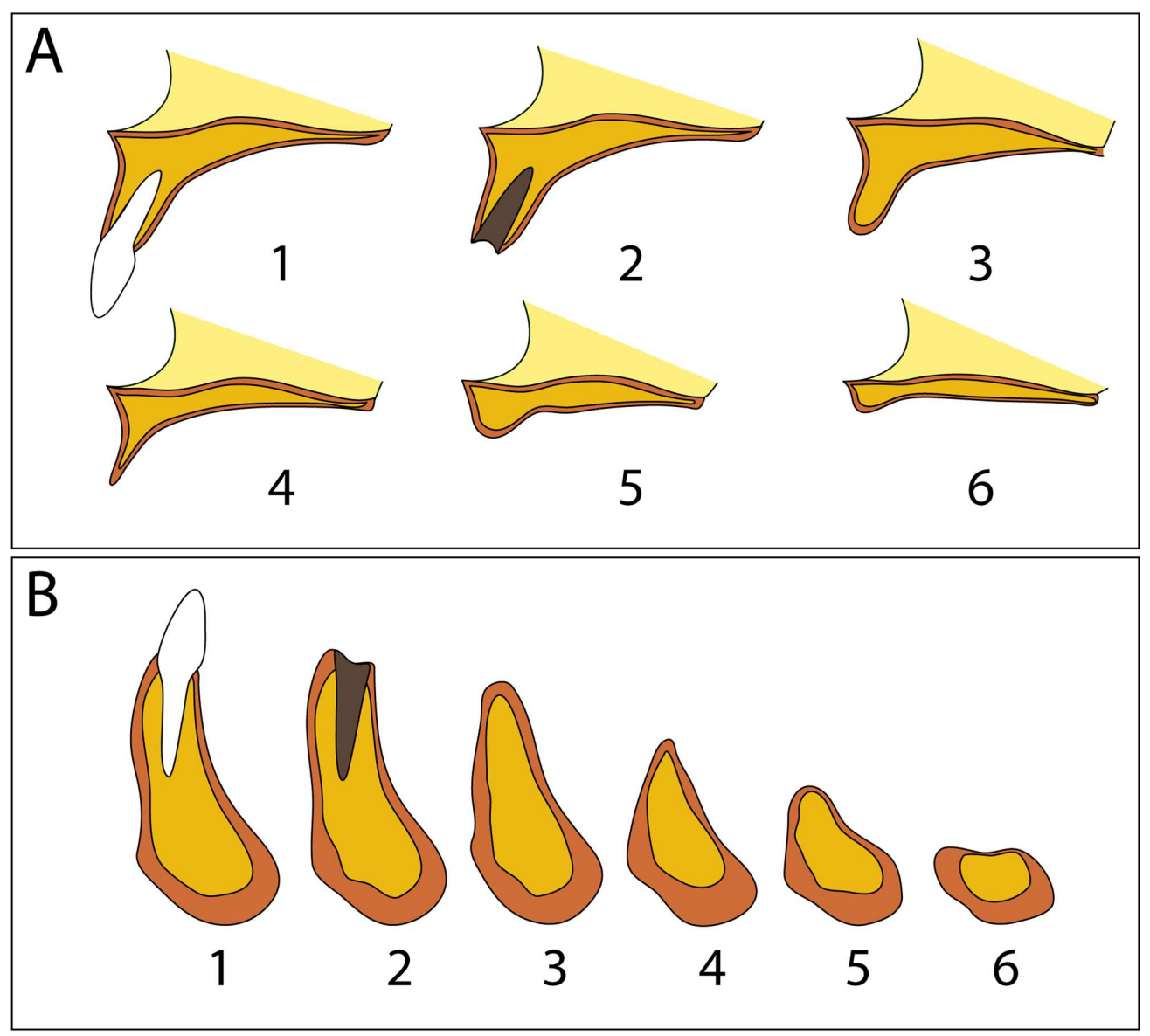

Figure 2: Classification system of six atrophy stages in the maxilla (A) and the mandible (B) according to Atwood (1963) and Cawood and Howell (1988). Atrophy stage 1: preextraction, stage 2: postextraction, stage 3: high well-rounded ridge, stage 4: knife-edge shaped ridge, stage 5: low well-rounded ridge, stage 6: depressed bone level. $85 \times 76 \mathrm{~mm}(600 \times 600 \mathrm{DPI})$ 

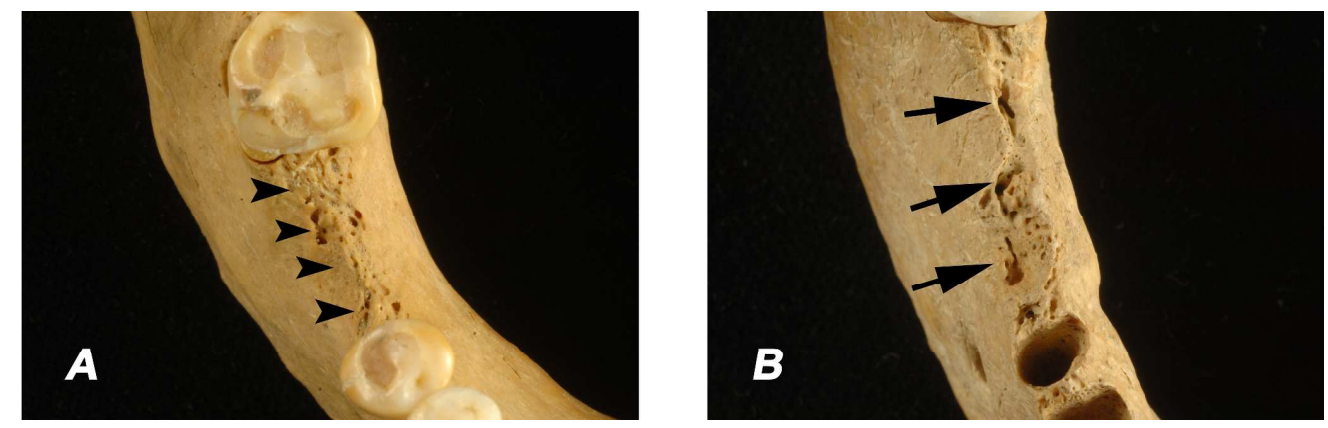

Figure 3: Photographs of two mandibular (right) posterior segments illustrating the differences between the features exposed trabecular bone and bony defects. (A) Area of exposed trabecular bone at the crest of the residual ridge (small black arrowheads). (B) Bony defects at the crest of the residual ridge (black arrowheads). $175 \times 55 \mathrm{~mm}(600 \times 600 \mathrm{DPI})$ 


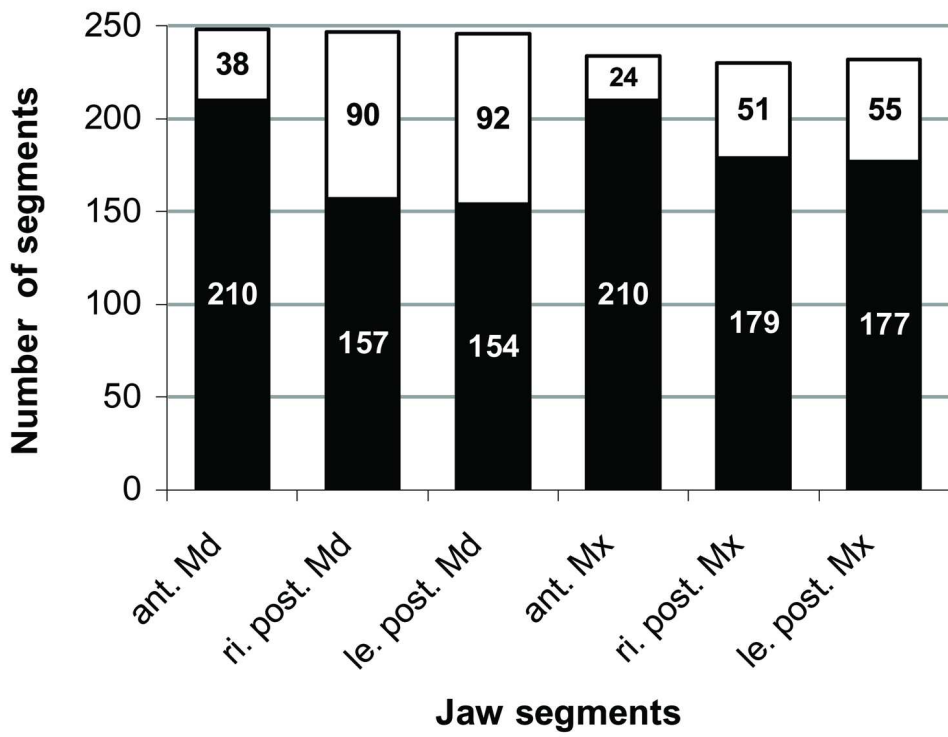

$\square$ postextraction \& atrophy-affected: stages 2 - 6

non-affected (preextraction): stage 1

Figure 4: Prevalence of atrophy (stages 2 to 6 ) and of the non-affected state before tooth loss (stage 1) in anterior and posterior segments of the mandible and the maxilla. Jaw segments: le. $=$ left, ri=right, ant.=anterior, post.=posterior, Md.=mandible, Mx.=maxilla. $85 \times 50 \mathrm{~mm}(600 \times 600 \mathrm{DPI})$ 
Young individuals (20-40 years)

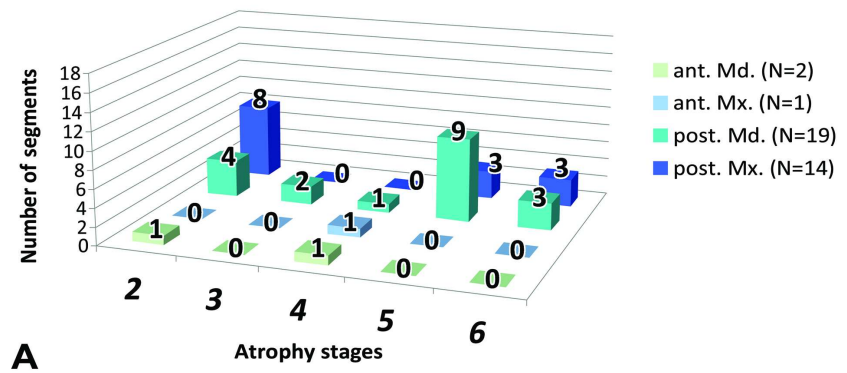

Middle-aged individuals (41-60 years)

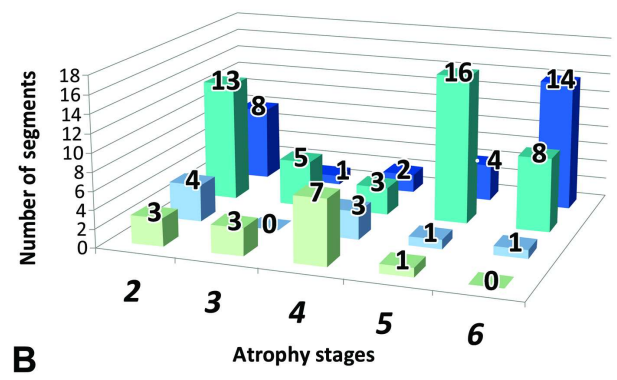

ant. Md. $(\mathrm{N}=14)$

ant. $\mathrm{Mx} .(\mathrm{N}=9)$

post. Md. $(\mathrm{N}=45)$

post. $\mathrm{Mx}$. $(\mathrm{N}=29)$

Old individuals (61-80 vears)

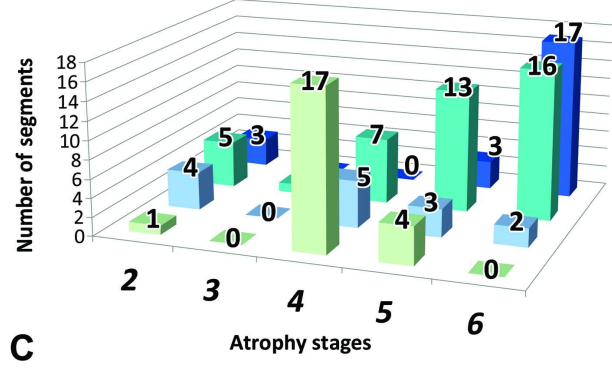

ant. Md. ( $\mathrm{N}=22)$

ant. $\mathrm{Mx} .(\mathrm{N}=14)$

post. $\mathrm{Md}$. ( $\mathrm{N}=42)$

nost. $\mathrm{Mx} .(\mathrm{N}=23)$

Figure 5: Frequency distribution of the atrophy stages 2 to 6 (postextraction to depressed bone level) in the jaw segments of young (A), middle-aged (B) and old individuals (C). Due to the low frequency of atrophy in young individuals data were presented as absolute values instead of percents. By this means, the total increase of affected segments is evident. Atrophy stages: $2=$ postextraction, $3=$ high well-rounded, $4=$ knife-edge, $5=$ low well-rounded, $6=$ depressed. Jaw segments: ant. $=$ anterior, post. $=$ posterior, $M d .=$ mandible, $M x .=$ maxilla. $85 \times 152 \mathrm{~mm}(600 \times 600 \mathrm{DPI})$ 